\title{
Respiratory abnormalities among workers in an iron and steel foundry
}

\author{
A JOHNSON, '* MOIRA CHAN-YEUNG, ' LONIA MACLEAN,' ELIZABETH ATKINS,' \\ ANN DYBUNCIO,' F CHENG,$^{2}$ AND D ENARSON'
}

From the Occupational Diseases Research Unit, ' Department of Medicine, Vancouver General Hospital, University of British Columbia, Vancouver, British Columbia, and the Engineering Section, ${ }^{2}$ Workers' Compensation Board of British Columbia, Vancouver, Canada

\begin{abstract}
A study of the health of 78 workers in an iron and steel foundry in Vancouver, British Columbia, was carried out and the results compared with those found in 372 railway repair yard workers who were not significantly exposed to air contaminants at work. The foundry workers were exposed to PepSet, which consists of diphenyl methane diisocyanate (MDI) and phenol formaldehyde and their decomposition products as well as to silica containing particulates. A questionnaire was administered by trained interviewers, and chest radiography, allergy skin tests, pulmonary function tests, and methacholine inhalation tests were carried out as well as measurement levels of dust and MDI. Compared with the controls, the foundry workers had more respiratory symptoms and a significantly lower mean $\mathrm{FEV}_{1}$ and $\mathrm{FEF}_{25-75 \%}$ after adjustments had been made for differences in age, height, and smoking habit. Three workers $(4.8 \%)$ had radiographic evidence of pneumoconiosis and $12(18.2 \%)$ had asthma defined as presence of bronchial hyperreactivity, cough, and additional respiratory symptoms such as wheeze, chest tightness, or breathlessness. Sensitisation to MDI is probably the cause of asthma in these workers.
\end{abstract}

After several workers in a foundry in Vancouver had been admitted to hospital with acute dyspnoea in the previous six months, the labour union requested the occupational diseases research unit of the University of British Columbia to conduct a health study in 1981. The foundry housed all operations within one building including metal melting, mould and core making, pouring of molten metal into moulds, shaking out casts from moulds, and grinding of irregularities from casts. The workers were exposed to several air contaminants including sand containing silica, metal dust, and chemicals used as binders for mould and core making, as well as a variety of gaseous emissions derived from the thermal decomposition of the chemical binders. The latter included carbon monoxide, carbon dioxide, hydrocarbons, carbonyl sulphide; hydrogen sulphide, sulphur dioxide, phenols, benzene, toluene, metaxylene, orthoxylene, naphthalene, formal-

*Present address: City Hospital, Department of Medicine, University of Edinburgh, Edinburgh, UK.

Received 10 January 1983

Accepted 6 March 1984 dehyde, acrolein, aldehydes, nitrogen oxides, hydrogen cyanide, ammonia, and aromatic amines. The concentrations of these gaseous products differed for different binding systems. ${ }^{1}$

This foundry has used several chemical binding systems over the years. In late 1979 PepSet (Ashland Chemicals Ltd) was first introduced into the foundry. This consists of three different components, diphenyl methane diisocyanate (MDI), phenol formaldehyde, and a catalyst containing a pyridine derivative. By later 1980 it had replaced all other binders. In addition to the workers admitted to hospital because of acute dyspnoea several workers complained of sore throat, eye and nose irritation, and headache.

\section{Materials}

All 78 workers in the foundry participated in the study and all gave written consent. Since they worked inside one building they were exposed to a certain extent to all the air contaminants in the foundry. As controls, we studied 372 railway yard repair workers in Squamish, British Columbia, representing $95 \%$ of the work force. These workers 
were not significantly exposed to air contaminants as determined by environmental measurements during the health study. The $16(20.5 \%)$ non-whites among the foundry workers and $42(11.3 \%)$ among the controls were excluded from the analysis because of racial differences in lung function; 20 women from the control group were also excluded. The railway yard repair workers were chosen as they were blue collar workers with a socioeconomic status similar to that of the foundry workers.

\section{Methods}

\section{HEALTH STUDY}

The health study was conducted at the plant site. A questionnaire based on American Lung Association recommendations ${ }^{2}$ was administered in a standard manner by trained interviewers. It contained detailed questions on respiratory symptoms together with questions on family history, present and past medical history, and occupational history including prior and current employment with emphasis on work activity and location.

One doctor (AJJ) examined the hands and chest of each worker and assessed the productiveness of their cough. Allergy skin tests were performed by the prick method on the volar aspect of the forearm using house mite (Dermatophagoides farinae), mixed Pacific grass pollen, and cat fur with a positive control of histamine $2.5 \mathrm{mg} / \mathrm{ml}$ and negative control of saline. Tests were read at 15 minutes and the transverse diameter of the weal measured. Men reacting to one or more allergens with a weal diameter of $3 \mathrm{~mm}$ or more were regarded as atopic.

Chest radiographs were obtained from 63 workers only as the remaining 15 men were not available at the time of the examination. The $x$ ray films were read by two independent observers according to the International Labour Organisation classification for pneumoconiosis. $^{3}$

All workers in the foundry were asked to undergo a bronchial challenge test with methacholine except those with heart disease, those taking drugs, such as beta blockers that might have interacted, or those whose forced expiratory volume in one second $\left(F_{1}\right)$ was $1.5 \mathrm{l}$ or less. Before the survey, four Bennett twin nebulisers were standardised for output at $51 / \mathrm{min}$ flow rate. $\mathrm{FEV}_{1}$ and forced vital capacity (FVC) were recorded on a Collins 13.51 water seal spirometer. Measurements were made in triplicate before the inhalation challenge. Physiological saline was nebulised at $5 \mathrm{l} / \mathrm{min}$ using oxygen as the carrier gas for a period of two minutes and each worker received the aerosol through a face mask during tidal breathing. Spirometry was repeated immediately after inhalation and four minutes later.
The physiological saline was a control inhalation and was followed by methacholine at increasing concentrations at $0 \cdot 5,1,2,4,8$, and $25 \mathrm{mg} / \mathrm{ml}$; inhalation and spirometry at each concentration were as detailed as for physiological saline. Inhalation was discontinued if $\mathrm{FEV}_{1}$ fell $20 \%$ compared with the lowest recording after physiological saline. From this the provocation concentration required to cause a $20 \%$ fall in $\mathrm{FEV}_{1}$ (the $\mathrm{PC}_{20}$ ) was calculated by interpolation. If such a reaction occurred the worker was given salbutamol inhalation $(200 \mu \mathrm{g})$ and $\mathrm{FEV}_{1}$ measurements were repeated until the FEV ${ }_{1}$ rose to preinhalation range before the man was allowed to return to work. Methacholine challenges were performed in a building some distance from the foundry between $8.30 \mathrm{am}$ and $5 \mathrm{pm}$, except for those on the graveyard shift who were tested at $11 \mathrm{pm}$. The challenge tests were performed on 66 workers, 12 being excluded for the medical reasons stated above. They were not performed on any railway yard repair workers.

Spirometric measurements only were carried out on the control subjects but lung volumes and diffusing capacity were also measured in the foundry workers. Spirometry was carried out using a dry rolling seal spirometer with the workers in the sitting position wearing a nose clip. A minimum of three acceptable forced expiratory manoeuvres were obtained after one or two trials. FEV, FVC, and maximum mid-expiratory flow rate $\operatorname{FEF}_{(25-75 \%)}$ were calculated out by computer and the mean $\mathrm{FEV}_{1}$ and $\mathrm{FEF}_{(25-75 \%)}$ of the two best tracings were recorded for each worker. Residual lung volume was measured using the nitrogen wash out method $^{4}$ from which the total lung capacity was calculated. Diffusing capacity $\left(\mathrm{DL}_{\mathrm{CO}}\right)$ was determined by the single breath technique. $^{5}$

\section{ENVIRONMENTAL MONITORING}

Measurements of the concentrations of quartz and MDI were carried out during the health survey by the engineering section of the Workers' Compensation Board of British Columbia. Other contaminants were not measured because of the shortage of industrial hygienists at the time of the study.

Personal sampling of respirable dust was carried out using a pump with a flow rate of $1.9 \mathrm{l} / \mathrm{min}$ for a period of seven hours. A two stage cyclone size selector preloaded with a $25 \mathrm{~mm}$ cellulose Ester membrane filter of $3 \mu \mathrm{m}$ pore size was attached to the pump. After sampling, the filter was ashed and a potassium bromide pellet made of the ash. The infrared spectrum of the sample was scanned and the absorbance determined at $12.5 \mu \mathrm{m}$. The amount of quartz in the sample was determined by comparison with the absorbances of pellets containing 
known amount of quartz. ${ }^{6}$ The permissible concentration (PC) of respirable dust was calculated as:

$\mathrm{PC}=\frac{10 \mathrm{mg} / \mathrm{m}^{3} \text { Respirable dust collected }}{\% \text { Respirable quartz }+2}$

As, for technical reasons, measurement of MDI could not be performed by personal sampling area sampling was carried out at multiple sites in the foundry. The isocyanate was collected by drawing a measured volume of air through a midget impinger containing a dilute solution of hydrochloric and acetic acids using a flow rate of $1-2 \mathrm{l} / \mathrm{min}$. Determination of the isocyanate level was carried out by diazotising and coupling $\mathbf{N}$-(1-naphthyl) ethylenediamine to the toluene-diamine or methylene bisphenyl amine produced by the hydrolysis of the isocyanate in the absorbing solution to produce a purple coloured dye that was measured spectrophotometrically at $550 \mathrm{~nm}^{7}$ The depth of colour was compared with the absorbance of a series of standards measured under the same condition to determine the amount of MDI in the sample. The concentration of MDI was calculated as follows:

\section{Molar volume}

Parts per million $(\mathrm{ppm})=\mathrm{mg} / \mathrm{m}^{3} \times$ molecular weight:

$\mathrm{mg} \mathrm{MDI} / \mathrm{m}^{3}$ Air $=\frac{\mu \mathrm{g} \text { Isocyanate per sample }}{\text { Air volume in litres. }}$

Molar volume of MDI at $25^{\circ} \mathrm{C}$ and $760 \mathrm{~mm} \mathrm{Hg}=$ $24 \cdot 66$, molecular weight of $\mathrm{MDI}=248 \mathrm{~g}$.

\section{Results}

CHARACTERISTICS OF WORKERS

Table 1 shows the characteristics of the foundry workers and the controls. The foundry workers were older, slightly shorter, and had been employed for

Table 1 Characteristics of the foundry and railway workers

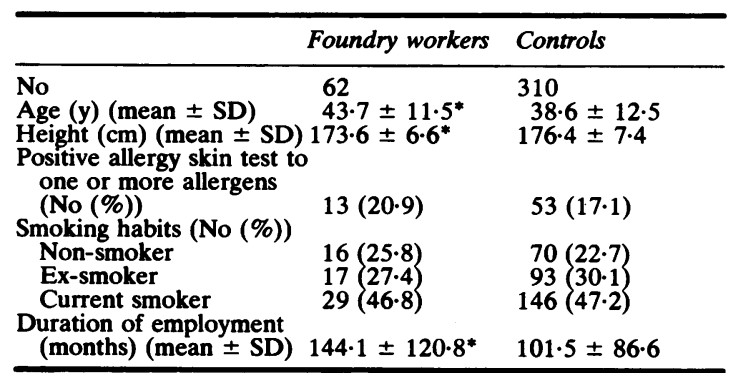

*Differences between foundry workers and controls are statistically significant at $p<0.05$ level by analysis of variance or chi-square, whichever is appropriate.
Table 2 Prevalence of respiratory symptoms. (Percentages in parentheses)

\begin{tabular}{|c|c|c|}
\hline & Foundry workers & Controls \\
\hline No & 62 & 310 \\
\hline \multicolumn{3}{|l|}{ Cough: } \\
\hline $\begin{array}{l}\text { Non-smokers } \\
\text { Ex-smokers }\end{array}$ & $1(5.9)$ & $\begin{array}{l}4(5 \cdot 1) \\
4(4 \cdot 4)\end{array}$ \\
\hline Current smokers & $16(55 \cdot 2)$ & $50(34 \cdot 2)$ \\
\hline Total & $18(29.0)$ & $58(18.7)$ \\
\hline \multicolumn{3}{|l|}{ Phlegm: } \\
\hline Non-smokers & $2(12 \cdot 5)$ & $5(7 \cdot 1)$ \\
\hline Ex-smokers & $4(23 \cdot 5)$ & $10(10 \cdot 8)$ \\
\hline Current smokers & $18(62 \cdot 1)^{* *}$ & $45(30 \cdot 8)$ \\
\hline $\begin{array}{l}\text { Total } \\
\text { Wheeze: }\end{array}$ & $24(38 \cdot 7)^{* *}$ & $60(19.4)$ \\
\hline Non-smokers & \multicolumn{2}{|c|}{ Wheeze: } \\
\hline Ex-smokers & $3(17 \cdot 6)$ & $9(9.7)$ \\
\hline Current smokers & $12(41 \cdot 4)$ & $39(26 \cdot 7)$ \\
\hline Total & $16(25 \cdot 8)$ & $55(17.7)$ \\
\hline \multicolumn{3}{|l|}{ Breathlessness: } \\
\hline Non-smokers & $2(12 \cdot 5)$ & $6(8 \cdot 6)$ \\
\hline Ex-smokers & $6(35 \cdot 3)$ & $14(15 \cdot 1)$ \\
\hline $\begin{array}{l}\text { Current smokers } \\
\text { Total }\end{array}$ & $14(48 \cdot 3)^{*}$ & $40(27 \cdot 4)$ \\
\hline \multicolumn{2}{|l|}{ Chest tightness: } & $60(19 \cdot 4)$ \\
\hline Non-smokers & $4(25 \cdot 0)$ & $10(14 \cdot 3)$ \\
\hline Ex-smokers & $6(35 \cdot 3)$ & $17(18 \cdot 3)$ \\
\hline Current smokers & $14(48 \cdot 3)^{*}$ & $37(25 \cdot 3)$ \\
\hline Total & $24(38 \cdot 7)^{* *}$ & $64(20 \cdot 6)$ \\
\hline \multicolumn{3}{|l|}{ Chest illness: } \\
\hline Non-smokers & $0(0)$ & $12(17 \cdot 1)$ \\
\hline Ex-smokers & $5(29 \cdot 4)$ & $10(10 \cdot 8)$ \\
\hline Current smokers & $15(51 \cdot 7)^{* *}$ & $18(12 \cdot 3)$ \\
\hline \multirow{2}{*}{\multicolumn{3}{|c|}{ Chronic bronchitis: }} \\
\hline & & \\
\hline Non-smokers & $0(0)$ & $1(1.4)$ \\
\hline Ex-smokers & $1(5 \cdot 9)$ & $4(4 \cdot 3)$ \\
\hline $\begin{array}{l}\text { Current smokers } \\
\text { Total }\end{array}$ & $\begin{array}{l}10(34 \cdot 5) \\
11(17 \cdot 7)\end{array}$ & $\begin{array}{l}23(15 \cdot 8) \\
28(9 \cdot 0)\end{array}$ \\
\hline
\end{tabular}

Differences between foundry workers and controls statistically significant at $\mathrm{p}<0.05\left(^{*}\right), \mathrm{p}<0.005\left(^{* *}\right)$ by chi-square analysis.

longer than the controls. There was no difference in smoking habit nor in the proportion of workers with a positive allergy skin test to one or more of the common allergens.

\section{PREVALENCE OF RESPIRATORY SYMPTOMS}

Table 2 shows the prevalence of respiratory symptoms among the foundry workers and the controls. For this analysis cough was defined as cough on most days for as much as three months a year, phlegm was defined similarly, wheeze as wheeze without colds, breathlessness as breathless when hurrying on the level or climbing up a slight hill, chest tightness as chest tightness associated with difficulty in breathing, chest illness as any chest illness during the past three years that kept them from work for as long as one week, and chronic bronchitis as cough and phlegm on most days for as much as three months a year for two successive years. The foundry workers had a higher prevalence of almost all respiratory symptoms irrespective of smoking habit. For phlegm, breathlessness, chest tightness, and chest illness the differences between the foundry 
Table 3 Effects of various factors on lung function by analysis of covariance

\begin{tabular}{|c|c|c|c|c|c|c|}
\hline \multirow[t]{2}{*}{ Factors } & \multicolumn{2}{|l|}{$F E V_{1}$} & \multicolumn{2}{|l|}{$F V C$} & \multicolumn{2}{|l|}{$F E F_{25-75} \%$} \\
\hline & Slope coefficient & p Value & Slope coefficient & p Value & Slope coefficient & p Value \\
\hline $\begin{array}{l}\text { Age } \\
\text { Age }^{2} \\
\text { Height }\end{array}$ & $\begin{array}{r}-41.69 \\
-\quad 0.38 \\
35.09\end{array}$ & $\begin{array}{r}<0.0001 \\
0.0877 \\
<0.0001\end{array}$ & $\begin{array}{r}-38.65 \\
-0.41 \\
56.42\end{array}$ & $\begin{array}{r}<0.0001 \\
0.0940 \\
<0.0001\end{array}$ & $\begin{array}{r}-62.40 \\
-\quad 0.33 \\
6.89\end{array}$ & $\begin{array}{r}<0.0001 \\
0.2738 \\
0.3170\end{array}$ \\
\hline \multirow{2}{*}{$\begin{array}{l}\text { Exposure } \\
\text { Smoking } \\
\text { Exposure and } \\
\text { smoking }\end{array}$} & - & $\begin{array}{r}<0.0001 \\
0.0001\end{array}$ & - & $\begin{array}{r}<0.0001 \\
0.0390\end{array}$ & - & $\begin{array}{l}0.0004 \\
0.3730\end{array}$ \\
\hline & - & $0 \cdot 2060$ & - & 0.0300 & - & 0.3730 \\
\hline $\begin{array}{l}\text { Duration of } \\
\text { employment }\end{array}$ & 0.41 & 0.3430 & 0.228 & 0.6230 & 0.87 & 0.4270 \\
\hline
\end{tabular}

Table 4 Pulmonary function tests (Mean $\pm S D$ )

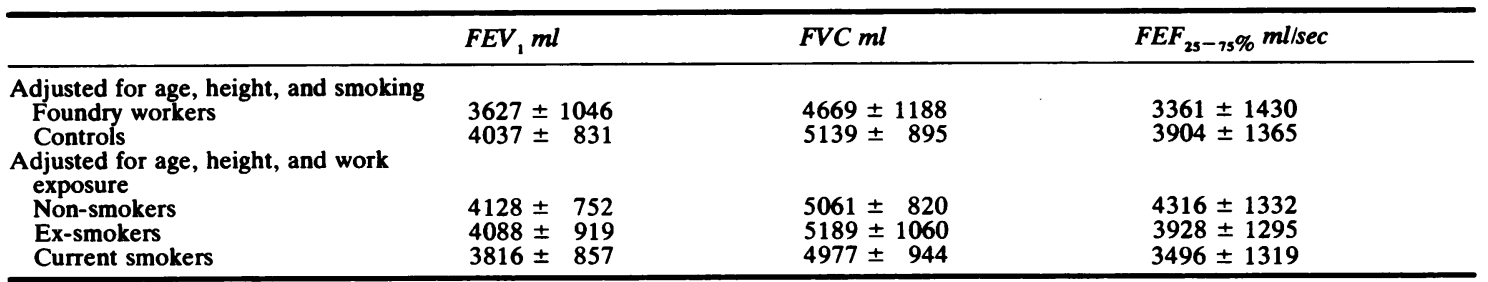

workers and the controls were statistically significant. Among non-smokers and ex-smokers, the prevalence of most of the respiratory symptoms, though higher in the foundry workers than the controls, failed to reach statistical significance. Among current smokers, all the chest symptoms except cough and wheeze were significantly more common among the foundry workers. As expected, current smokers had a significantly higher prevalence of all chest symptoms than non-smokers irrespective of the work group.

\section{PREVALENCE OF PHYSICAL SIGNS}

The prevalence of wet cough was significantly higher among the foundry workers than the controls (20.5\% $v 9.5 \%$ respectively). The prevalence of rales and rhonchi was also higher among the foundry workers than the controls but this difference was not statistically significant.

\section{PULMONARY FUNCTION TESTS}

The effects of age, height, exposure, smoking, and duration of employment were examined by analysis of covariance; the results are shown in table 3. As expected age, height, and smoking significantly affected lung function. Work exposure in the foundry also significantly influenced lung function but the duration of employment did not, after adjustment for age. Table 4 shows the results of the pulmonary function tests, according to exposure group adjusted for age, height, and smoking and according to smoking group adjusted for age, height, and work exposure. The mean $\mathrm{FEV}_{1}, \mathrm{FVC}$, and $\mathrm{FEF}_{25-75 \%}$ of the foundry workers were all significantly lower than those of the controls. Current smokers had significantly worse mean lung function than nonsmokers (see table 3 for statistical analysis).

Measurements of subdivisions of lung volume and diffusing capacity were carried'out only on the foundry workers and the results were all within normal limits using prediction equations derived from published reports. ${ }^{89}$

\section{METHACHOLINE CHALLENGE TEST}

The data from non-whites have been included in table 5 which shows the results of the methacholine challenge test. We have arbitrarily taken a methacholine $\mathrm{PC}_{20}>8 \mathrm{mg} / \mathrm{ml}$ as normal and a $\mathrm{PC}_{20}$ $\leqslant 8 \mathrm{mg} / \mathrm{ml}$ as an indication of the presence of hyperreactive airways. Using this criterion, $19.7 \%$ of the foundry workers had evidence of bronchial hyperreactivity; current smokers had a higher prevalence of bronchial hyperreactivity than non-smokers

Table 5 Prevalence of bronchial hyperreactivity in foundry workers*

\begin{tabular}{llcc}
\hline & \multicolumn{2}{l}{ Methacholine $P C \leqslant 8 \mathrm{mg} / \mathrm{ml}$} \\
\cline { 2 - 3 } & Total & No & $\%$ \\
\hline Non-smokers & 31 & 3 & $9 \cdot 7$ \\
Ex-smokers & 13 & 3 & 23.1 \\
Current smokers & 22 & 7 & 31.8 \\
Combined & 66 & 13 & 19.7 \\
\hline
\end{tabular}

*Includes data from non-whites. 
Table 6 Summary of industrial hygiene data

\begin{tabular}{lc}
\hline Respirable mass: & \\
No of samples taken & $48(100-0)$ \\
Mean, $\mathrm{mg} / \mathrm{m}^{3}$ & 1.26 \\
Range, $\mathrm{mg} / \mathrm{m}^{3}$ & $0 \cdot 13-13 \cdot 52$ \\
No of samples above PC* & $(41 \cdot 7)$ \\
MDI level: & $319(100 \cdot 0)$ \\
No of samples taken & $273(85 \cdot 6)$ \\
$<0.005 \mathrm{ppm}$ & $27(8.5)$ \\
$>0.005-<0.010 \mathrm{ppm}$ & $14(4.4)$ \\
$>0.010-<0.015 \mathrm{ppm}$ & $3(0.9)$ \\
$>0.015-<0.020 \mathrm{ppm}$ & $2(0.6)$ \\
$>0.020$ & \\
\hline
\end{tabular}

${ }^{*} \mathrm{PC}=$ Permissible concentration.

$(31.8 \% \vee 9.7 \%$ respectively). The results were essentially similar when non-whites were excluded from the analysis.

All the workers with bronchial hyperreactivity with the exception of one non-smoking non-white, had one or more respiratory symptoms. Among the whites, the results of the lung function tests of those with bronchial hyperreactivity were significantly lower than those without bronchial hyperreactivity after adjustment had been made for age, height, and smoking.

\section{CHEST RADIOGRAPHS}

Three radiographs $(4.8 \%)$ were interpreted by both readers independently to have evidence of pneumoconiosis with profusion category $1 / 0$ and higher. Four more radiographs were interpreted by one reader only to have evidence of pneumoconiosis as defined above. No restrictive ventilatory defect was found in any of the workers with radiographic abnormalities.

\section{INDUSTRIAL HYGIENE DATA}

The industrial hygiene data are summarised in table 6. Twenty of the 48 samples collected by personal sampling had a respirable dust level above the permissible concentration. Only two samples, however, had a concentration of MDI above the permissible concentration of $0.02 \mathrm{ppm} .^{10}$ It should be pointed out that several months before this study the foundry had installed a new ventilation system above the moulding machines. Before the installation, levels of MDI in excess of $0.02 \mathrm{ppm}$ were found on several occasions.

\section{Discussion}

In this study we have found that foundry workers as a group had a higher prevalence of almost all respiratory symptoms and chronic bronchitis than a group of controls; their mean $\mathrm{FEV}_{1}$ and $\mathrm{FEF}_{25-75 \%}$ were also significantly lower than the controls after adjustments had been made for differences in age, height, and smoking habit. In any study of occupational health it is difficult to find a control group matched perfectly for all factors except exposure at work and so the differences observed between the two groups could possibly be due to the railway yard workers being particularly healthy. We compared the results of the lung function tests of the railway workers with a group of 136 workers employed by the City Hall of Vancouver and were unable to find any significant differences in lung function between the railway yard workers and the City Hall workers which would indicate that the railway yard workers are particularly healthy.

While cigarette smoking, as expected, adversely affected the lung function of the workers in both groups, exposure to air contaminants in the foundry also significantly impaired lung function. That the duration of employment had no significant effect on the lung function of the foundry workers is because age and duration of employment are highly correlated. In the analysis of covariance age and an age square term were entered as independent variables; after adjusting for these two variables, the effect of duration of employment became no longer significant.

The health hazards arising from exposure of diisocyanates particularly to toluene diisocyanate (TDI) have been widely studied during the past decade as they are being increasingly used in industry. Exposure to high concentrations of TDI gives rise to acute irritation of the skin, eyes, and respiratory tract and chemical bronchitis and bronchopneumonia may also occur. ${ }^{11}$ Long term exposure to low concentrations of TDI $(<0.02 \mathrm{ppm})$ has given rise to impairments of lung function ${ }^{12-15}$ and typical attacks of bronchial asthma ${ }^{16-20}$ and hypersensitivity pneumonitis ${ }^{20}$ due to TDI exposure have also been reported. MDI, one of the components of PepSet, is the second most commonly used isocyanate and it has been thought to be less harmful than TDI because of its low vapour pressure. Nevertheless, inhalation of droplets or vapours of MDI has given rise to respiratory irritation and sometimes asthmatic attacks ${ }^{1121-23}$ and hypersensitivity pneumonitis due to MDI exposure has also been reported..$^{23}$ The other component of PepSet is phenol formaldehyde. Formaldehyde is a known irritant to skin and the respiratory tract. It has given rise to asthma in exposed workers and, typically, late asthmatic reactions have been induced on inhalation challenge. ${ }^{25}$

In this study if one defines asthma as the presence of bronchial hyperreactivity (methacholine $\mathrm{PC}_{20} \leqslant 8$ $\mathrm{mg} / \mathrm{ml}$ ) together with cough and one of the following symptoms, wheeze, chest tightness and dyspnoea 12 foundry workers (including non-whites) had asthma. 
The levels of MDI in the foundry before the installation of the new ventilation system were higher than the currently accepted permissible concentration of $0.02 \mathrm{ppm},{ }^{10}$ hence, possibly, the workers were "sensitised" to MDI. In a later study we performed inhalation provocation tests with MDI and formaldehyde on nine of the asthmatic workers. Six developed a specific asthmatic reaction to MDI but not to formaldehyde, indicating that MDI was the cause of their asthma. ${ }^{26}$

Three workers $(4.8 \%)$ had evidence of pneumoconiosis on independent reading of their radiographs. Four more radiographs were read by the second reader as having evidence of pneumoconiosis of category $1 / 0$, although none of the workers had a restrictive ventilatory defect. The total dust concentration in the foundry has been high over the years and during the present survey, $41.7 \%$ of the samples taken were found to be above the permissible concentration. Silicosis is a well known occupational lung disease in foundry workers $^{27}$; since these workers are also exposed to other dusts such as iron oxide, a mixed dust pneumoconiosis may occur rather than classic silicosis. In larger series the prevalence of pneumoconiosis in foundry workers varies from $3.8 \%$ to $14 \% .{ }^{28-30}$

Karava et al showed that among ferrous and nonferrous foundry workers, chronic bronchitis occurred more frequently among those in the dusty jobs and that smoking increased the prevalence of chronic bronchitis in a synergistic manner ${ }^{29}$ Mikov confirmed this finding and showed that the mean $\mathrm{FEV}_{1}$ of foundry workers was considerably lower than that of a control group irrespective of the smoking habit. ${ }^{31}$ In the present study we also found a higher prevalence of chronic bronchitis in the foundry workers than in the controls; exposure to dusts, chemicals, and cigarette smoking probably all contributed to the higher prevalence of chronic bronchitis.

We thank the management of the foundry and the Canadian Association of Industrial Mechanical and Allied Workers Union for their cooperation, the Workers' Compensation Board of British Columbia for industrial hygiene measurements, Dr David Muir for acting as a second reader of the chest radiographs, and Mrs Ellen Wong for her secretarial help.

\section{References}

\footnotetext{
' Scott WD, Bates CE, James RH. Chemical emissions from foundry molds. American Foundrymen's Society Transactions 1977;85:203-8.
}

${ }^{2}$ Recommended respiratory questionnaire for use with adults and children in epidemiological research. Am Rev Respir Dis 1978:118, part 2:7-53.

${ }^{3}$ International Labour Office. U/E 1971. International classification of radiographic of pneumoconiosis. Med Radiogr Photogn 1972;48:67-97.

${ }^{4}$ Darling RC, Cournand A, Richards DW, Jr. Studies on intrapulmonary mixture of gases. III-an open circuit method for measuring residual air. J Clin Invest 1940;19:609-18.

${ }^{5}$ Forster RE, Fowler NS, Bates DV, Van Lingen B. The absorption of carbon monoxide by the lungs during breathholding. $J$ Clin Invest 1954;33:1135-45.

- Cares JW, Golding AS, Lynch JJ, Burgess WA. The determination of quartz in airborne respirable granite dust by infra-red spectroscopy. Am Ind Hyg Assoc J 1973;34:298-305.

' Marcali K. Microdetermination of toluene diisocyanates in atmosphere. Anal Chem 1957;29:552-8.

${ }^{8}$ Boren HW, Kory RC. The veterans administration army cooperative study of pulmonary function. 2 . The lung volume and its subdivisions in normal men. Am J Med 1966;41:96114.

' Goldman HL, Becklake M. Respiratory functions tests. Normal values at median altitudes and the prediction of normal results. Am Rev Tuberc Pulm Dis 1959;79:457-67.

${ }^{10}$ Criteria for a recommended standard: occupational exposure to diisocyanate. Atlanta Georgia: US Department of Health, Education and Welfare, NIOSH, 1978. (Publ No 78-215.)

" Munn A. Hazards of isocyanates. Ann Occup Hyg 1965;8:1639.

12 Peters JM, Murphy RLH, Ferris BG. Ventilatory function in workers exposed to low levels of toluene-diisocyanate: a six month follow-up. Br J Ind Med 1969;26:115-20.

${ }^{13}$ McKenows CB, Davie HJ, Parry Jones A. Symptoms and lung function following acute and chronic exposure to toluene diisocyanate. Proceedings of the Royal Society of Medicine 1970;63:376-8.

14 Butcher BT, Jones RN, O'Neil C, et al. Longitudinal study of workers employed in the manufacture of toluene-diisocyanate. Am Rev Respir Dis 1977;116:411-21.

is Adams WGF. Long-term effects on the health of men engaged in the manufacture of toluene-diisocyanate. $\mathrm{Br} \mathrm{J}$ Ind $\mathrm{Med}$ 1975;32:72-8.

${ }^{16}$ Sweet LC. Toluene diisocyanate asthma. University of Michigan Medical Centre Journal. 1968;34:27-9.

17 Pepys J, Pickering CAC, Breslin ABX, Terry DI. Asthma due to inhaled chemical agents in toluene diisocyanates. Clin Allergy 1972;2:225-36.

${ }^{18}$ Butcher BT, Salvaggio JE, Weill H, Ziskind MM. Toluene diisocyanate (TDI) pulmonary disease: immunologic and inhalation challenge studies. J Allergy Clin Immunol 1976;58:89100.

${ }^{19}$ O'Brien IM, Newman-Taylor AJ, Burges PS, Harris MG, Fawcett IW, Pepys J. Toluene diisocyanate induced asthma. II. Inhalation challenge tests and bronchial reactivity studies. Clin Allergy 1979;9:7-15.

${ }^{20}$ Charles J, Bernstein A, Jones B, et al. Hypersensitivity pneumonitis ... after exposure to isocyanate. Thorax 1976;31:127-36.

${ }^{21}$ Konzen RB, Croft BF, Scheel LD, Gorski CH. Human response to low concentrations of $\mathrm{p}$ p-diphenylmethane diisocyanate. Ann Ind Hyg Assoc J 1966;27:121-7.

${ }^{22}$ Tanser AR, Bomke MP, Blandford AG. Isocyanate asthma: respiratory symptoms caused by diphenyl-methane diisocyanate. Thorax 1973;28:596-601.

${ }^{23}$ Zeiss CR, Kanellakes TM, Bellone JD, Levitz D, Pruzansky JJ, Patterson R. Immunoglobulin E-mediated asthma and hypersensitivity pneumonitis with precipitin anti-hapten antibodies due to diphenylmethane diisocyanate (MDI) exposure. $J$ Allergy Clin Immunol 1980;63:345-52.

${ }_{24}$ Malo J, Zeiss CR. Occupational hypersensitivity pneumonitis after exposure to diphenylmethane diisocyanate. Am Rev 
Respir Dis 1982;125:113-6.

${ }^{25}$ Hendrick DJ, Lane DJ. Occupational formalin asthma. Br J Ind Med 1977;34:11-8.

${ }^{26}$ Zammit-Tabona M, Sherkin M, Kijek M, Chan H, Chan-Yeung M. Asthma caused by diphenyl methane diisocyanate in foundry workers. Clinical, bronchoprovocation and immunologic studies. Am Rev Respir Dis 1983;128:226-30.

${ }^{27}$ McLaughlin AIG. Industrial lung disease of iron and foundry workers. London: HMSO, 1950.
${ }^{28}$ Lloyd-Davies TA. Respiratory disease in foundry man. Report of a survey. London: HMSO, 1971.

${ }^{24}$ Karava R, Hernberg S, Koskela RS, Luoma K. Prevalence of pneumoconiosis and chronic bronchitis in foundry workers. Scand J Work Environ Health 1976;2, suppl 1:64-72.

${ }^{30}$ Gregory J. A survey of pneumoconiosis at a Sheffield steel foundry. Arch Environ Health 1970;20:385-400.

${ }^{31}$ Mikov MI. Chronic bronchitis in foundry workers in Vojrodina. Arch Environ Health 1974;29:261-7. 